\title{
Plasma cholesterol after myocardial infarction
}

\author{
SUSAN G. COTTON* \\ M.B., M.R.C.P. \\ Grimshaw-Parkinson Research Student, University of Cambridge
}

\begin{abstract}
Summary
Serial plasma cholesterol estimations were made at intervals up to 13 weeks after myocardial infarction in fourteen men. Wide fluctuations in these levels, occasionally in excess of $100 \mathrm{mg} / 100 \mathrm{ml}$ were found during the first 3 weeks and subsequently.

The general trend was towards lowest levels about the end of the first week. The 3-week level was frequently not typical of subsequent levels, which may have been influenced by seasonal variation and body weight changes.
\end{abstract}

\section{Introduction}

The tendency for plasma (or serum) cholesterol levels to fluctuate considerably during the early weeks after myocardial infarction may be insufficiently appreciated in this country. This tendency has obvious relevance in the matter of recognition and characterization of hyperlipidaemic patients in this group, with possible prognostic and therapeutic implications. This report concerns the findings in a small group of men similar to that studied by Watson, Buchanan \& Dickson (1963) who found an early fall in the cholesterol level with return to a higher, stable level about the end of the third week.

\section{Subjects and methods}

The fourteen patients studied were all men between 38 and 65 years of age when admitted to hospital with myocardial infarction. The diagnosis was confirmed by ECG and (in twelve cases) by SGOT elevation. Ten patients were treated with anticoagulants, contraindications being present in the other four. None had diabetes, thyroid disorder, nephrotic syndrome or other disease known to effect plasma cholesterol levels.

The study was carried out between December, 1968 and the end of July, 1969. Blood samples were drawn between 8.0 a.m. and 9.0 a.m. after a 12hour fast (necessitated by contemporaneous assay of other lipid moieties including triglyceride and free fatty acids). The first sample was thus taken on the first or second day after admission. Further samples were taken at 1,2 and 3 weeks after admission and then, after discharge, at 9 and 13 weeks.

Plasma cholesterol was measured by an automated method based on the reagent described by Huang et al. (1961). The laboratory error did not exceed $\pm 10 \mathrm{mg} / 100 \mathrm{ml}$ over the range of cholesterol levels encountered.

\section{Results}

These are shown in the accompanying table. The mean and $95 \%$ confidence limits for the group at each sampling time are shown in Fig. 1.

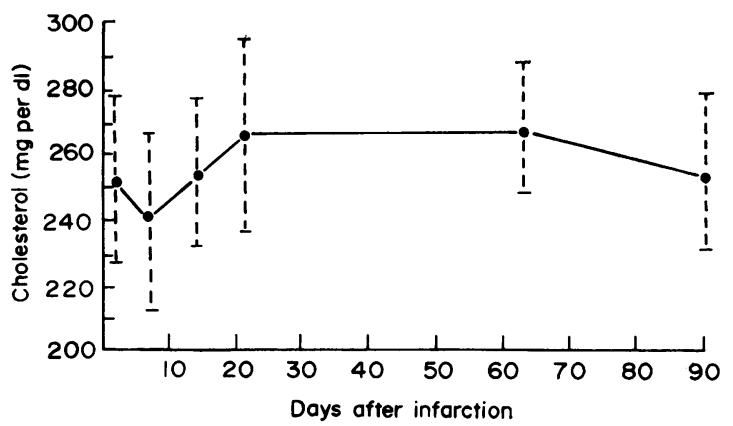

Fig. 1. Mean plasma cholesterol levels (with $95 \%$ confidence limits) at stated times post-infarction.

There is a downward trend in the first week (as also found by Logan \& Murdoch, 1966), followed by a tendency for the cholesterol level to rise during the next 2 weeks. The apparent fall between the ninth and thirteenth week was of interest. However, none of these changes reaches currently acceptable levels of significance.

\section{Discussion}

Much greater individual variability characterized this series than was found in the patients studied by Watson et al. (1963). All fourteen in their group 
TABLE 1. The plasma cholesterol levels in each individual at stated time after myocardial infarction

\begin{tabular}{lccccccc}
\hline & \multirow{6}{*}{$\begin{array}{c}\text { Age } \\
\text { Patient }\end{array}$} & \multicolumn{6}{c}{ Plasma cholesterol levels (mg/100 ml) } \\
\cline { 3 - 7 } & & First & Week 1 & Week 2 & Week 3 & Week 9 & Week 13 \\
\hline 1. J.J. & 62 & 180 & 163 & 165 & 180 & 263 & 212 \\
2. A.R. & 56 & 270 & 250 & 300 & 375 & 315 & 292 \\
3. F.B. & 53 & 295 & 260 & 270 & 270 & 280 & 233 \\
4. D.C. & 54 & 200 & 165 & 185 & - & 205 & 185 \\
5. T.D. & 51 & 225 & 195 & 245 & 270 & 240 & 200 \\
6. C.V. & 64 & 247 & 270 & 282 & 272 & 282 & 282 \\
7. D.N. & 50 & 252 & 288 & 258 & 259 & 260 & 305 \\
8. J.A. & 43 & 210 & 200 & 235 & 223 & 225 & 219 \\
9. F.C. & 50 & 247 & 240 & 275 & 225 & 275 & 255 \\
10. S.P. & 39 & 270 & 278 & 300 & 300 & 308 & 252 \\
11. E.G. & 54 & 226 & 240 & 226 & 269 & 270 & 280 \\
12. A.D. & 65 & 265 & 270 & 280 & 290 & 330 & 325 \\
13. C.C. & 47 & 252 & 258 & 247 & 194 & 228 & 268 \\
14. W.T. & 56 & 345 & - & 285 & 305 & 270 & 260 \\
Mean & & 252 & 240 & 255 & 267 & 268 & 255 \\
& & & & & & & \\
95\% Confidence & & 26 & 27 & 23 & 29 & 21 & 24 \\
limits \pm & & & & & & & \\
\hline
\end{tabular}

showed a fall in cholesterol level by day 6 (but their earlier first sample may be an important difference) and fluctuations during the subsequent rise were few in number and perhaps no greater than the method error. Anti-coagulant therapy was reported to be immaterial in this respect.

This small study confirms the tendency of the plasma cholesterol level to undergo considerable fluctuation during the early weeks after myocardial infarction (Biörck, Blomquist \& Sievers, 1957; Kuo, 1960; Ravel 1969). The trend appears to be as found in the other longitudinal study covering several weeks (Watson et al., 1963) but the pattern of lowest level at sixth to ninth day post-infarction, followed by a rise to the twenty-second day, is not regularly seen in all cases.

In this series the downward trend in plasma cholesterol between the ninth and thirteenth week could be related to weight reduction insofar as the seven patients showing a definite fall in cholesterol over this period also showed a mean weight loss of approximately $3 \mathrm{lb}$ at the relevant time. Another possibility is that the coincidence of seasonal variation affected the plasma cholesterol levels at this stage. Nine patients, including the seven showing definite fall in cholesterol level, had their 13-week plasma samples taken between the beginning of May and the end of July and at this time of year lower plasma cholesterol levels may prevail, (Doyle, Kinch \& Brown, 1965; Carlson \& Lindstedt, 1969).

\section{Acknowledgments}

I wish to thank Dr D. W. Evans for his help with this investigation; Drs T. M. Chalmers and A. P. Dick for kindly allowing me to see their patients; Dr M. P. Walsh for carrying out the biochemical estimations and Miss $\mathbf{J}$. Nixon, Department of Human Ecology, University of Cambridge for statistical advice. Thanks are also due to John Bonnet Clinical Laboratories for facilities granted and to Mrs A. Bond for skilled technical assistance.

\section{References}

Biörck, G., Blomquist, G. \& Sievers, J. (1957) Cholesterol values in patients with myocardial infarction and in a normal control group. Acta Medica Scandinavica, 156, 493.

Carlson, L.A. \& Lindstedt, S. (1969) Stockholm prospect study: 1-Initials values for plasma lipids. Acta Medica Scandinavica, Supplement 493.

Doyle, J.T., KINCH, S.A. \& Brown, D.F. (1965) Seasonal variation in Serum Cholesterol Concentration. Journal of Chronic Diseases, 18, 657.

Huang, T.C., Chen, C.P., Wefler, V. \& Raferty, A. (1961) A stable reagent for the Liebermann-Burchard Reaction. Analytical Chemistry, 33, 1405.

Kuo, P.T. (1960) Blood Cholesterol and other lipidsTheir association with Atherosclerosis. Medical Clinics of North America, 44, 1635.

LogAN, R.W. \& MURDoch, W.R. (1966) Blood-levels of hydrocortisone, transaminases and cholesterol after myocardial infarction. Lancet, ii, 521.

RAVEL, R. (1969) in Clinical Laboratory Medicine, Chapter 21, p. 235. Year Book Medical Publications, Chicago.

Watson, W.C., Buchanan, K.D. \& Dickson, C. (1963) Serum Cholesterol levels after myocardial infarction. British Medical Journal, 2, 709. 